\title{
Combined therapy of somatostatin analogues with pegvisomant for the treatment of acromegaly: a meta-analysis of prospective studies
}

Lingyun $\mathrm{Ma}^{1+}$, Daohuang Luo ${ }^{1,2+}$, Ting Yang ${ }^{1}$, Songtao $\mathrm{Wu}^{1,2}$, Min $\mathrm{Li}^{1}$, Chaoyang Chen ${ }^{1}$, Shuang Zhou', Lingyue $\mathrm{Ma}^{1}$, Ye $\mathrm{Wu}^{3}$, Ying $\mathrm{Zhou}^{1 *}$ and Yimin Cui ${ }^{1}$

\begin{abstract}
Background: Acromegaly is a rare, chronic and severe disease. Drug therapy including somatostatin analogues (SAs), dopamine receptor agonists and growth hormone receptor antagonists (pegvisomant, PEG) are commonly used to treat patients who do not respond to surgery. The use of combination therapy with PEG and SAs has become more common over the last decade. We performed this study to accurately evaluate the effect of combination therapy of SAs with PEG on acromegalic patients.
\end{abstract}

Methods: PubMed, EMBASE, The Cochrane Library, ClinicalTrials.gov, Scopus, Web of Science, Chinese Biomedical Literature Database and Trip database were searched for relevant studies. Prospective clinical trials treating acromegaly with the co-administration of SAs and PEG were included. We performed a meta-analysis by using Stata 12.1. Sensitivity analysis was conducted to explore heterogeneity.

Results: Nine studies were included in this meta-analysis. The overall rate of serum insulin-like growth factor 1 (IGF1) normalization was $66 \%\left(95 \% \mathrm{Cl}: 52-78 \% ; I^{2}=62.59 \%\right)$. The combination therapy did not significantly change patients' fasting plasma glucose (ES: $0.011 \mathrm{mmol}^{*} \mathrm{~L}^{-1} ; 95 \% \mathrm{Cl}$ : -0.374 to $0.397 \mathrm{mmol}^{*} \mathrm{~L}^{-1} ; P=0.954$ ) or glycosylated haemoglobin (ES: $-0.074 \%$; $95 \% \mathrm{Cl}:-0.166$ to $0.315 \%$; $P=0.544$ ) while decreasing the fasting plasma insulin (ES: $21.487 \mathrm{pmol}^{*} \mathrm{~L}^{-1} ; 95 \% \mathrm{Cl}$ : -35.713 to $-7.260 \mathrm{pmol}^{*} \mathrm{~L}^{-1} ; P=0.003$ ). Elevation of liver enzyme levels was found in $14 \%$ ( $95 \% \mathrm{Cl}: 8$ to $21 \%$ ) of the patients. There was no significant difference for serious adverse events and treatment discontinuation due to adverse event between SAs monotherapy group and combination therapy group.

Conclusions: Combined therapy of SAs and PEG effectively normalized IGF-1 levels in most of the patients whose IGF1 level was greater than the upper limit of normal after high dose SAs monotherapy. The therapy also decreased significantly FPI levels with a neutral effect on glucose parameters in acromegaly patients. Moreover, elevated liver enzyme levels were observed in a small number of patients, which suggests a need for liver function monitoring.

Trial registration: We have our protocol registered in PROSPERO. (Registration number: CRD42019115549).

Keywords: Somatostatin analogues, Pegvisomant, Acromegaly, Meta-analysis

\footnotetext{
*Correspondence: zhouying0321@126.com

${ }^{+}$Lingyun Ma and Daohuang Luo contributed equally to this work.

'Department of Pharmacy, Peking University First Hospital, No.6, Da Hong

Luo Chang Street, Beijing 100034, China

Full list of author information is available at the end of the article
}

\section{$\triangle B M C$}

C C The Author(s). 2020 Open Access This article is licensed under a Creative Commons Attribution 4.0 International License, which permits use, sharing, adaptation, distribution and reproduction in any medium or format, as long as you give appropriate credit to the original author(s) and the source, provide a link to the Creative Commons licence, and indicate if changes were made. The images or other third party material in this article are included in the article's Creative Commons licence, unless indicated otherwise in a credit line to the material. If material is not included in the article's Creative Commons licence and your intended use is not permitted by statutory regulation or exceeds the permitted use, you will need to obtain permission directly from the copyright holder. To view a copy of this licence, visit http://creativecommons.org/licenses/by/4.0/ The Creative Commons Public Domain Dedication waiver (http://creativecommons.org/publicdomain/zero/1.0/) applies to the data made available in this article, unless otherwise stated in a credit line to the data. 


\section{Background}

Acromegaly is a rare, chronic and severe disease in which growth hormone $(\mathrm{GH})$ is overproduced mainly due to $\mathrm{GH}$-secreting pituitary. GH circulates and stimulates production of insulin-like growth factor 1 (IGF-1) from the liver [1]. Therefore, serum levels of IGF-1 are usually used for assessment of disease control. Moreover, some acromegalic patients are bothered with impaired glucose tolerance and type 2 diabetes mellitus, with a prevalence of the latter ranging from 19 to $56 \%$ [2]. The mechanism is not completely understood, but it may be related to insulin resistance due to overproduction of $\mathrm{GH}$ [3].

Surgery is recommended as the first-line treatment option when an experienced surgeon is available and the tumour is resectable [4]. However, not all patients can be cured by surgery. Moreover, surgery of microadenomas has a remission rate of more than $85 \%[5,6]$. Thus, other strategies such as drug therapy are necessary in some acromegalic patients.

Currently, available medical treatments include somatostatin analogues (SAs: octreotide, lanreotide or pasireotide), dopamine receptor agonists and growth hormone receptor antagonists (pegvisomant (PEG)). SAs, which suppress GH secretion by binding to somatostatin receptors, remain the primary medical treatment option if surgery is not possible or curative [7]. The IGF-1 normalization rate of SAs monotherapy varies from 17 to $69 \%$ [8-12]. Different from SAs, PEG inhibits production of IGF-1 by binding to GH receptors and preventing their dimerization [13]. PEG monotherapy has been shown to be effective for normalization of IGF-1 in about $70 \%$ of cases $[14,15]$. As for the safety issue, an elevation of liver transaminase levels is the main adverse drug reaction in the patients treated with SAs or PEG [14]. There are two well-known types of hepatic enzyme disturbance: hepatocellular and cholestatic. Cholestatic disturbances are most often related to treatment with somatostatin analogues, hepatocellular to treatment with PEG [16]. In patients with unsatisfactory results after SAs monotherapy, PEG as monotherapy or in association with SAs is generally the next treatment attempt [7]. Recently, an analysis of the ACROSTUDY demonstrated that the use of combination therapy with PEG and SAs has become more common over the last decade [17].

A previous meta-analysis investigated glucose metabolism during the combination therapy [18]. However, the authors did not study other important efficacy such as IGF-1 or safety profile of the treatment. Therefore, as an update, we performed this meta-analysis to get an accurate and full picture of the effect of the combined SAs and PEG therapy on acromegalic individuals based on all published reports.

\section{Methods}

This meta-analysis was reported according to PRISMA statement.

\section{Search strategy}

We searched for studies in PubMed, EMBASE, The Cochrane Library, ClinicalTrials.gov, Scopus, Web of Science, Chinese Biomedical Literature Database and Trip database (up to February 2020). There were no limits on publication date. The following words were used to build the search strategies: acromegaly, octreotide, lanreotide, somatostatin, pasireotide and pegvisomant (see the full search strategy in Additional file 1).

\section{Inclusion and exclusion criteria}

Studies were included if they met the following eligibility criteria: (1) prospective trials; (2) patients diagnosed with acromegaly; (3) patients using an SAs in association with PEG; (4) the length of study was at least 3 months; and (5) studies reporting efficacy outcomes (IGF-1 normalization rate after the combination therapy) or glucose metabolism outcomes before and after the treatment or safety outcomes (the number or percentage of patients with elevated liver enzyme levels after the treatment, number or percentage of patients discontinuing treatment due to adverse events and number or percentage of patients with serious adverse event). We excluded reviews, retrospective studies, animal studies and publications not in English or Chinese.

Firstly, the identification of potentially relevant studies, by reviewing titles and abstracts, was completed by two authors. Then, the full texts of the remaining studies were reviewed by two authors independently to identify the final studies for meta-analysis. We solved any disagreements with open discussion.

\section{Data extraction and quality assessment}

Data were extracted from the included studies by two reviewers. If data were not reported, we contacted the corresponding authors to obtain necessary data. The following data were extracted: (1) study design; (2) baseline characteristics (number of patients, age, sex, previous treatment, the length of study, mean or median dosage of SAs and PEG); (3) number or percentage of patients with normalized age- and sex-adjusted IGF-I levels; (4) fasting plasma glucose (FPG), fasting plasma insulin (FPI), and glycosylated hemoglobin (HbA1c), before and after combination treatment; (5) number or percentage of patients with elevated liver enzyme levels; (6) number or percentage of patients discontinuing treatment due to adverse events in the combination therapy group and SAs monotherapy group; and (7) number or percentage of patients with serious adverse event in the combination therapy group and SAs monotherapy group. Only the last follow-up assessment was considered for all outcomes.

Quality assessment was performed by the investigators using the Cochrane risk-of-bias algorithm for controlled trials [19] and modified Methodological Index for Nonrandomized Studies [20] for non-comparative studies. 
GRADE was applied to assessed the evidence quality of two safety outcomes (serious adverse event and treatment discontinuation due to adverse event).

\section{Statistical analysis}

Meta-analysis was performed with Stata 12.1. Heterogeneity was evaluated via Chi-square and $\mathrm{I}^{2}$ statistical tests [21]. If the $\mathrm{I}^{2}$ of heterogeneity< $50 \%$, we will chose fixedeffects model, otherwise, the random-effects model will be chosen. Meta-analysis of event rates (normalization rate of IGF-1 level, elevation rate of liver enzyme level) were conducted using double arcsine transformation. The rates are presented with lower and upper limits of 95\% confidence intervals (CIs). The overall effect size of the other two safety outcomes (number or percentage of patients discontinuing treatment due to adverse events and number or percentage of patients with serious adverse event) was presented as odds ratio (OR) and $95 \% \mathrm{CI}$. We computed the mean difference between post-values and pre-values of other data (FPG, FPI, and HbA1c) and get summary statistics for the overall difference. The estimated effect size (ES) was reported as the mean difference and 95\% CIs.

To assess sensitivity, when the effect size was dependent on one or two trials (e.g. a large trial), these trials were dropped from the analysis. Statistical significance was assumed when $P$-values were less than 0.05 .

\section{Results}

\section{Literature screen}

We identified 3655 articles in PubMed, EMBASE, The Cochrane Library, ClinicalTrials.gov, Scopus, Web of Science, Chinese Biomedical Literature Database and Trip database. Of these, 318 were excluded due to being duplicates. We selected 24 studies after title and abstract screening. Finally, nine studies [2, 22-29] were included in the meta-analysis after full text reading. Figure 1 shows the flowchart of study selection.

\section{Study characteristics}

Among the nine studies included in this meta-analysis, two were RCT $[22,24]$, one was double-blind, placebocontrolled, crossover study [23], one was longitudinal comparative study [25], one was follow-up comparative study [26] and the remaining were non-comparative studies [2, 27-29].

Characteristics of all trials are shown in Table 1. Notably, the patients were treated with a high-dose firstgeneration SAs (octreotide or lanreotide) and PEG in all of the studies. All studies enrolled both male and female patients aged from 23 to 74 years old. Most of the patients received surgery as their initial therapy. Other previous treatments included radiotherapy and medical treatment (octreotide, lanreotide and cabergoline). The duration of the selected trials was also variable, ranging from 24 to 456 weeks.

\section{Quality assessment of studies}

The included studies had similar methodological quality and had no major defects in describing patient inclusion criteria, data collection and outcome evaluation (see the result of quality assessment in Additional file 2).

\section{Outcomes}

\section{IGF-1 normalization}

Four studies, 150 patients, were included in this analysis [2, 22, 27, 28]. In these studies, all patients had IGF-1 levels that were greater than the upper limit of normal (ULN) despite SAs monotherapy. Overall, the meta-

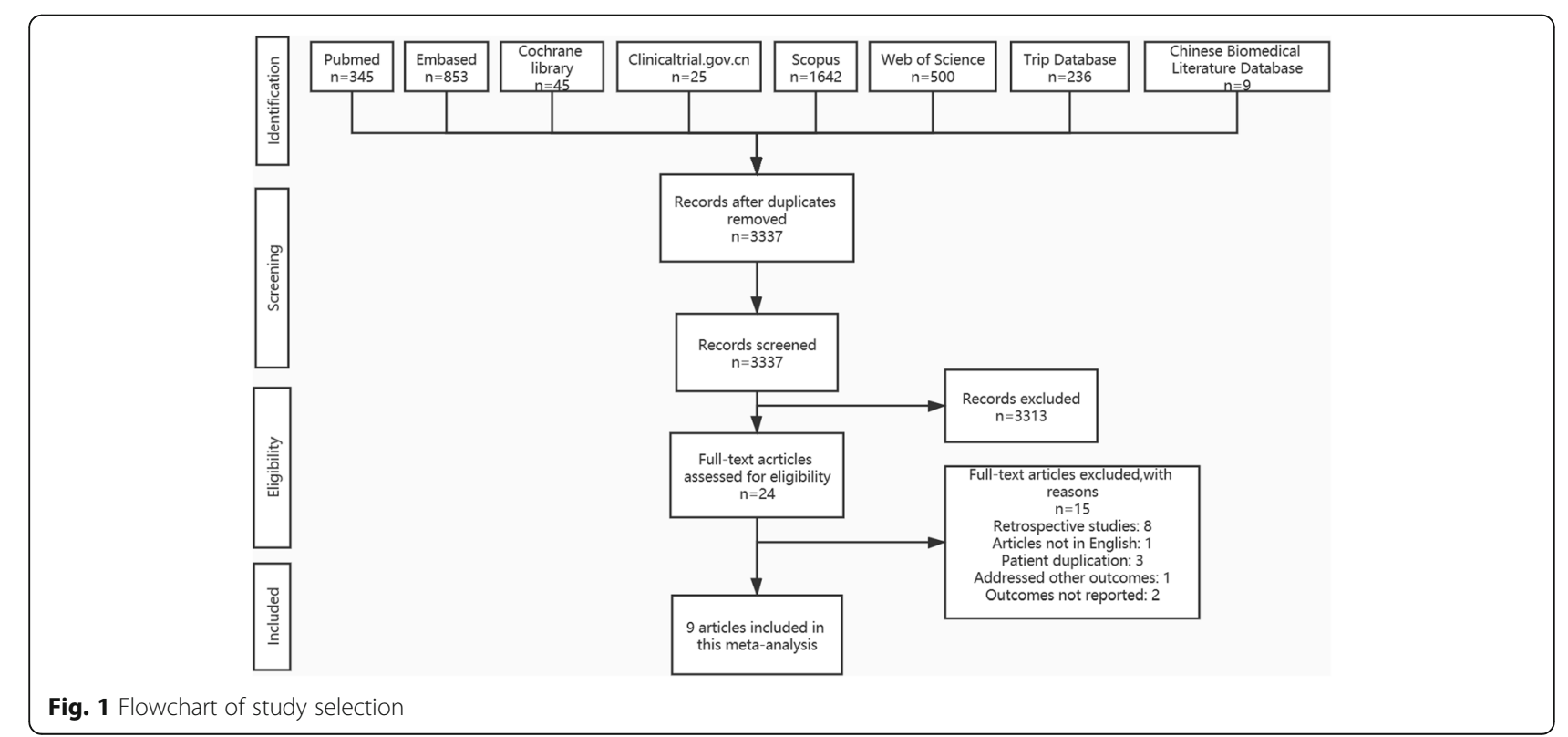




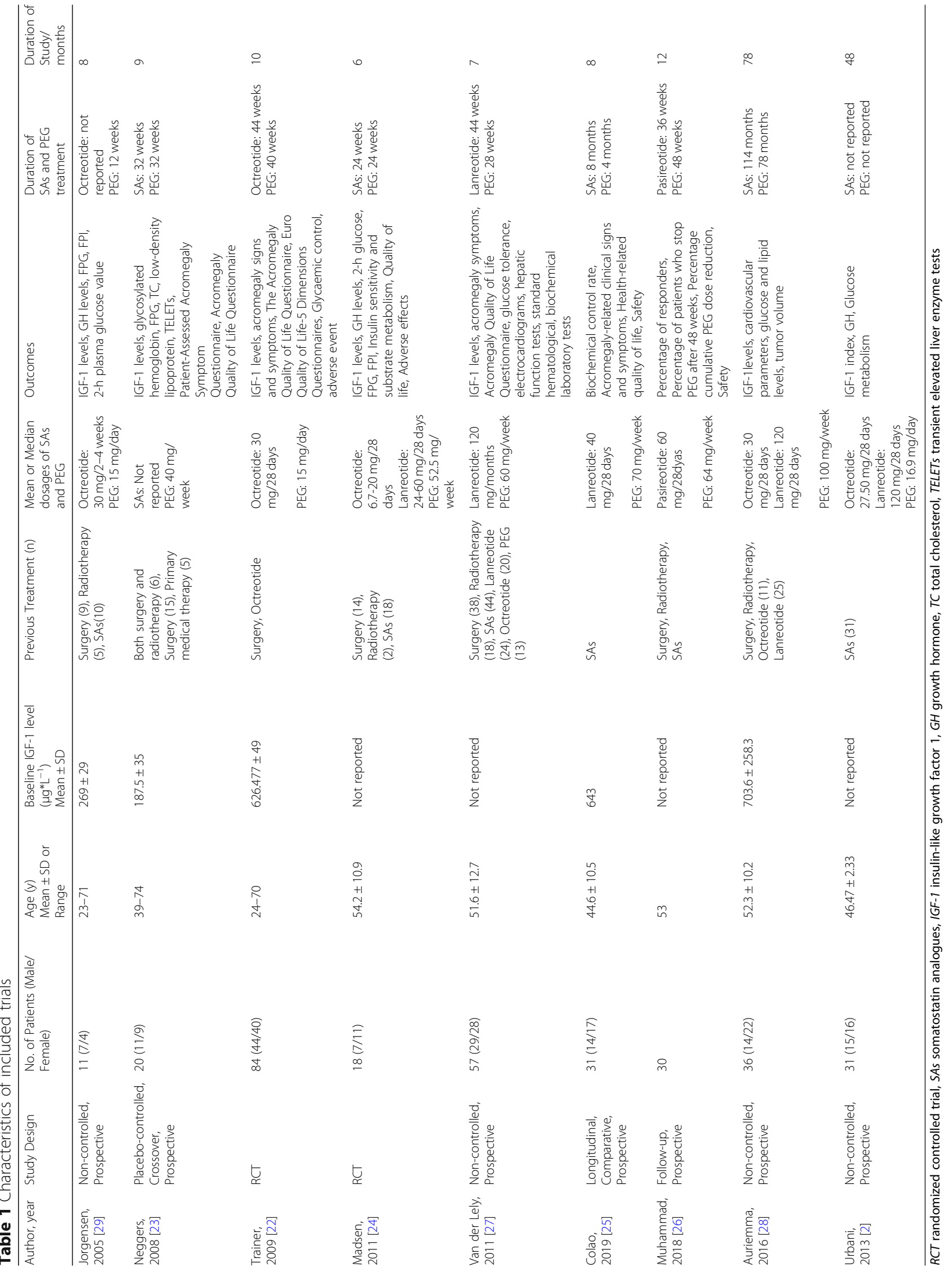


analysis demonstrated an IGF-1 normalization rate of 66\% (95\% CI: 52-78\%; Fig. 2), with high heterogeneity $\left(I^{2}=62.59 \%\right)$.

\section{Glucose metabolism}

Meta-analysis of 4 studies, 111 patients, [2, 27-29] showed that the combination therapy did not significantly affect FPG (ES: $0.011 \mathrm{mmol}^{*} \mathrm{~L}^{-1}$; $95 \% \mathrm{CI}:-0.374$ to $0.397 \mathrm{mmol}^{*} \mathrm{~L}^{-1}$; $I^{2}=83.7 \% ; P=0.954$ ) (Fig. 3). Four studies [2, 27-29], 111 patients, were included in the analysis of FPI (ES: -21.487 pmol" $\mathrm{L}^{-1}$; $95 \% \mathrm{CI}:-35.713$ to $\left.-7.260 \mathrm{pmol}^{*} \mathrm{~L}^{-1} ; P=0.003\right)$, with high heterogeneity $\left(I^{2}=76.0 \%\right)$, revealing significant change (Fig. 4). Five papers, 160 patients, reported HbA1c levels before and after treatment [2, 22, 26-28]. A NOT significant decrease was found (ES: $-0.074 \%$; $95 \%$ CI: -0.166 to $0.315 \% ; P=0.544)$, accompanied by high heterogeneity $\left(I^{2}=92.2 \%\right)$ (Fig. 5).

\section{Elevation in liver enzyme levels}

Four studies, 115 patients, were included in this analysis [22-24, 27]. Results demonstrated that the overall rate of elevation in liver enzyme levels was 14\% (95\% CI: 8 to $\left.21 \% ; I^{2}=0 \%\right)($ Fig. 6).

\section{Other safety outcomes}

We combined data for common safety outcomes reported in two comparative studies [22, 25], including serious adverse event and treatment discontinuation due to adverse event (Table 2). There was no significant difference between the combination therapy and SAs monotherapy. The evidence quality was low and moderate for serious adverse event and treatment discontinuation due to adverse event, respectively (see the result of evidence quality in Additional file 3).

\section{Sensitivity analysis}

Four meta-analyses showed high heterogeneity (Figs. 2, 3,4 and 5). Thus, sensitivity analysis was performed to explore the heterogeneity. After removal of van der Lely's and Muhammad's studies [26, 27], a significant decrease of HbA1c levels was found (ES: $-0.189 \%$; $95 \%$ $\mathrm{Cl}:-0.276 \%$ to $-0.102 \% ; P=0.000$ ), with no heterogeneity. For other outcomes, no significant differences were found compared with the initial analyses.

\section{Discussion}

This meta-analysis gave us a more accurate understanding of the effect of PEG in association with SAs on acromegaly.

This meta-analysis revealed that combination therapy of SAs and PEG normalized IGF-1 in $66 \%$ of patients whose IGF-1 levels were still higher than ULN despite high-dose of SAs monotherapy, which was in accordance with Leonart's study [15]. The meta-analysis showed high heterogeneity, the use of different assays for IGF-1 concentration and different PEG dose adjustment protocols may account for this variance.

Glucose metabolism impairment, from impaired glucose tolerance to severe diabetes mellitus, is frequently observed in acromegaly [30], which complicates the management of the disease. The prevalence of diabetes in acromegalic patients ranges from 20 to $56 \%$, and that of impaired glucose tolerance ranges from 16 to $46 \%$ [3]. Over the past few decades, the effect of SAs on glucose homeostasis remains open [31, 32]. SAs exert antisecretory and antiproliferative effects by acting on somatostatin receptors subtype 2 (SSTR-2) and SSTR-5 [33]. SSTR-2 is mainly involved in glucagon regulation while SSTR-5 plays a role in regulating insulin secretion [34].

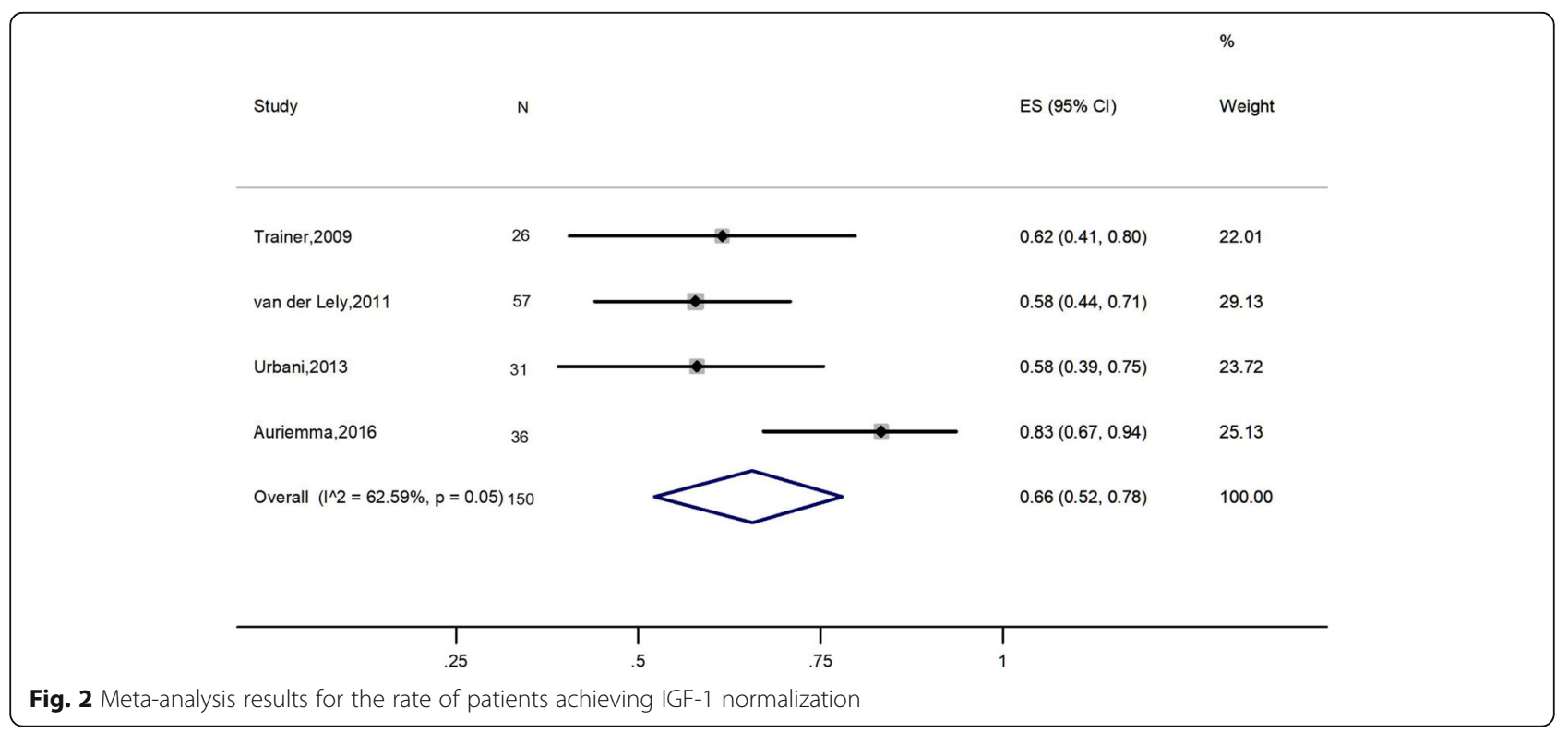




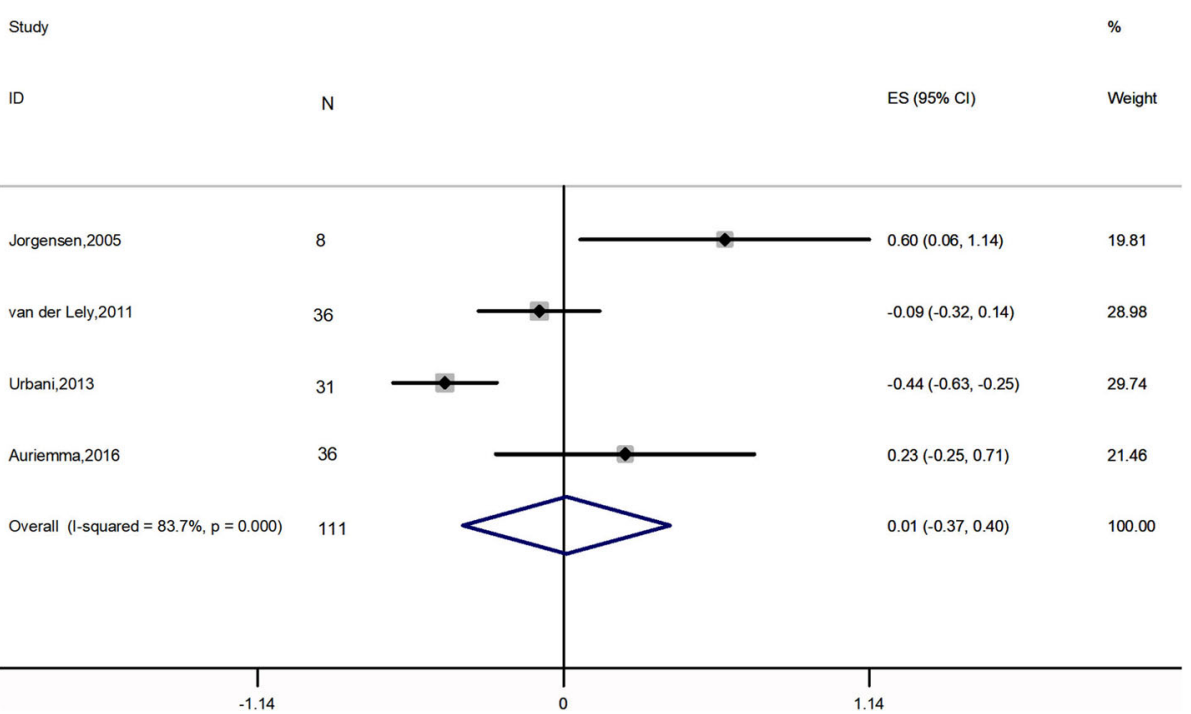

Fig. 3 Meta-analysis results for the change in fasting plasma glucose

In addition, glucagon-like peptide-1, which plays an important role as an incretin hormone, is also modulated by SAs [35]. All of these pathways lead to the raise or lowering of blood glucose levels. Thus, it is difficult to confirm the net effect of SAs on glucose metabolism. Conversely, several studies have shown that PEG monotherapy induced a significant decrease in fasting glucose levels and HbA1c in patients with diagnosed diabetes mellitus or impaired glucose tolerance [2, 36-38]. A recent meta-analysis demonstrated that PEG induces a considerable decrease in FPG, HbA1c, FPI and in homeostatic model assessment of insulin resistance [18]. A positive effect of PEG on peripheral insulin sensitivity has also been demonstrated [39]. According to our results, the combination of SAs and PEG lead to a significant decrease in FPI which is in agreement with the previous meta-analysis [18]. It was expected since both drugs have the same effect on FPI. However, the combined treatment did not change the patients' FPG or HbA1c levels, which is consistent with a previous study [18]. The reduced dose of PEG may be one of the reasons for this result. It is notable that a significant decrease of HbA1c level was found after the removal of two studies [26, 27]. Compared with other three studies [2, 22, 28], van der Lely's study [27] had the shortest follow-up period and the glucose metabolism outcomes were evaluated only in nondiabetic patients. A one-year study also found that the combined treatment improved HbA1c level of acromegalic patients [40]. We, therefore, assume that long-term combined

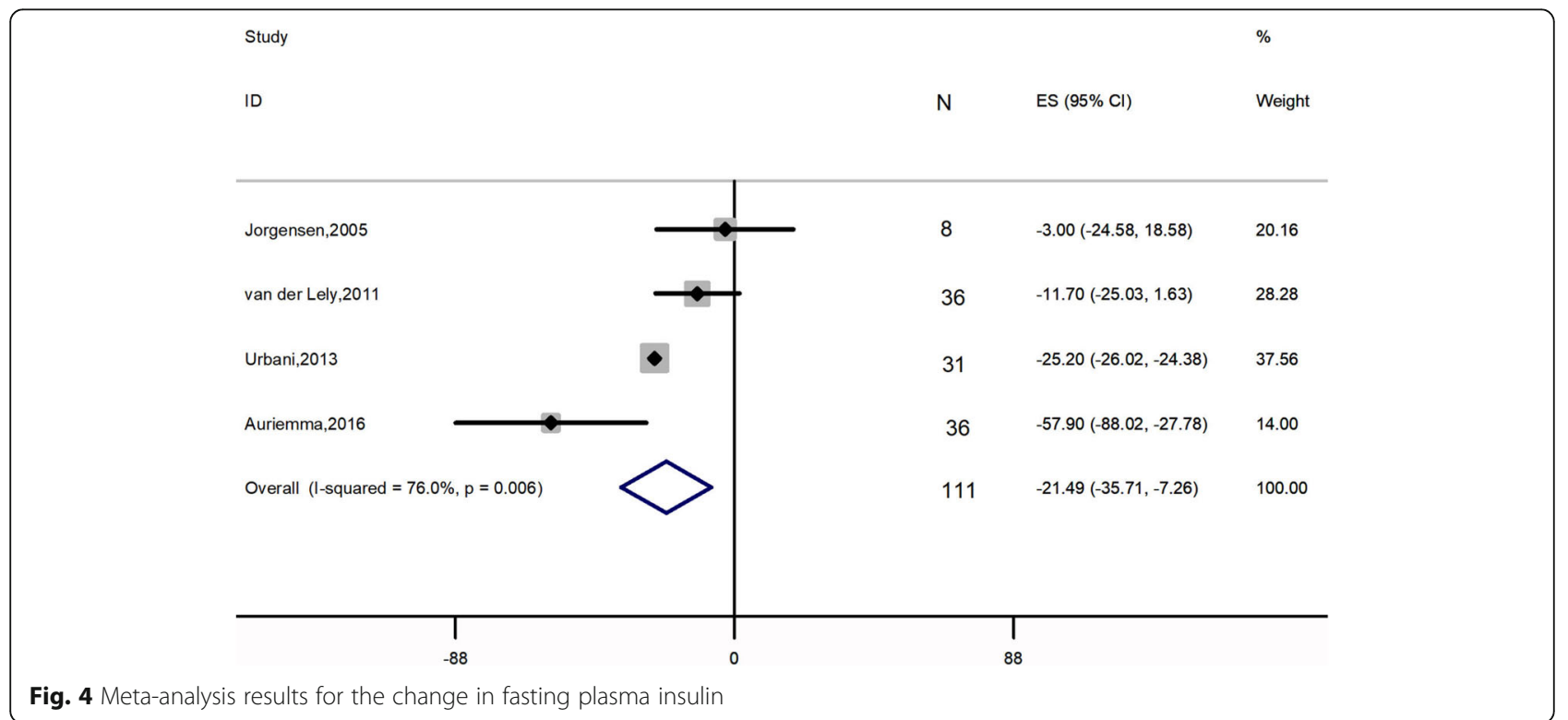




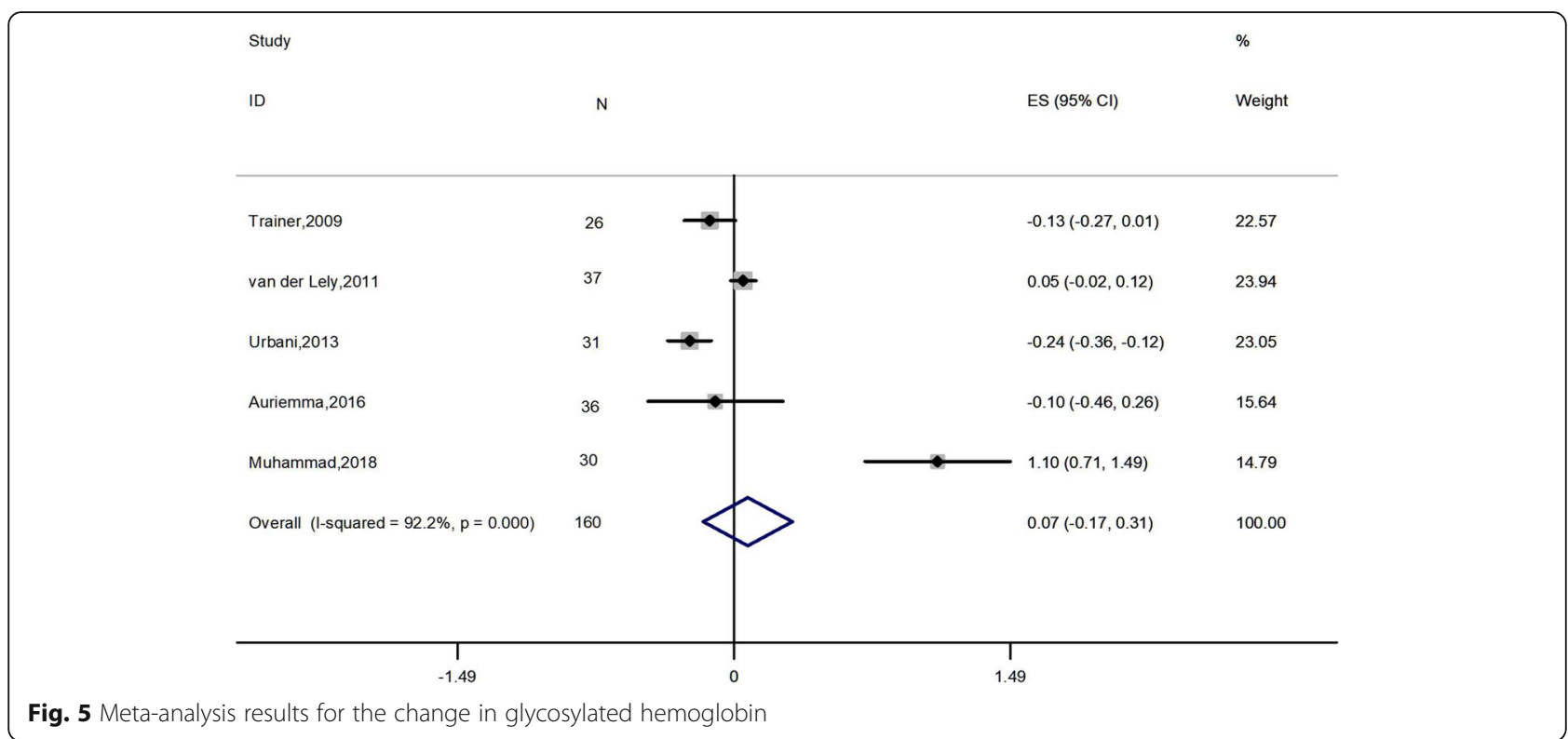

treatment may have a beneficial effect on HbA1c. Muhammad's study demonstrated that $\mathrm{HbA1c}$ level increased from 6.0 to $7.1 \%$ after the combination therapy [25]. The patients in Muhammad's study [25] were treated with pasireotide, a second-generation SAs, while patients in other four studies $[2,21,26,27]$ were treated with first-generation SAs, octreotide and lanreotide. A previous study showed that pasireotide may have worse effect on glucose metabolism compared with octreotide or lanreotide [41]. Overall, given the neutral global effect of PEG and SAs combination therapy on metabolic parameters, life style management and hypoglycemic drugs may be necessary in acromegalic patients who have impaired glucose tolerance or diabetes mellitus during PEG and SAs treatment.
Over the decades, SAs and PEG have been shown to be safe and well tolerated [42, 43]. Some surveillance studies $[36,44]$ reported an elevation of liver transaminase levels in approximately $5-8 \%$ of patients mainly previously treated with SAs. Transaminase level elevations during PEG treatment were often mild and transient [36]. The frequency of elevated liver enzymes seemed to increase in patients who were treated with a combination of SA and PEG [36]. In accordance with that, the present analysis of elevated liver enzymes showed an overall rate of $14 \%$. The abnormal biochemical parameters returned to normal after treatment discontinuation in most of the patients. Nevertheless, we recommend careful monitoring of liver function during the cotreatment. Interestingly, a previous

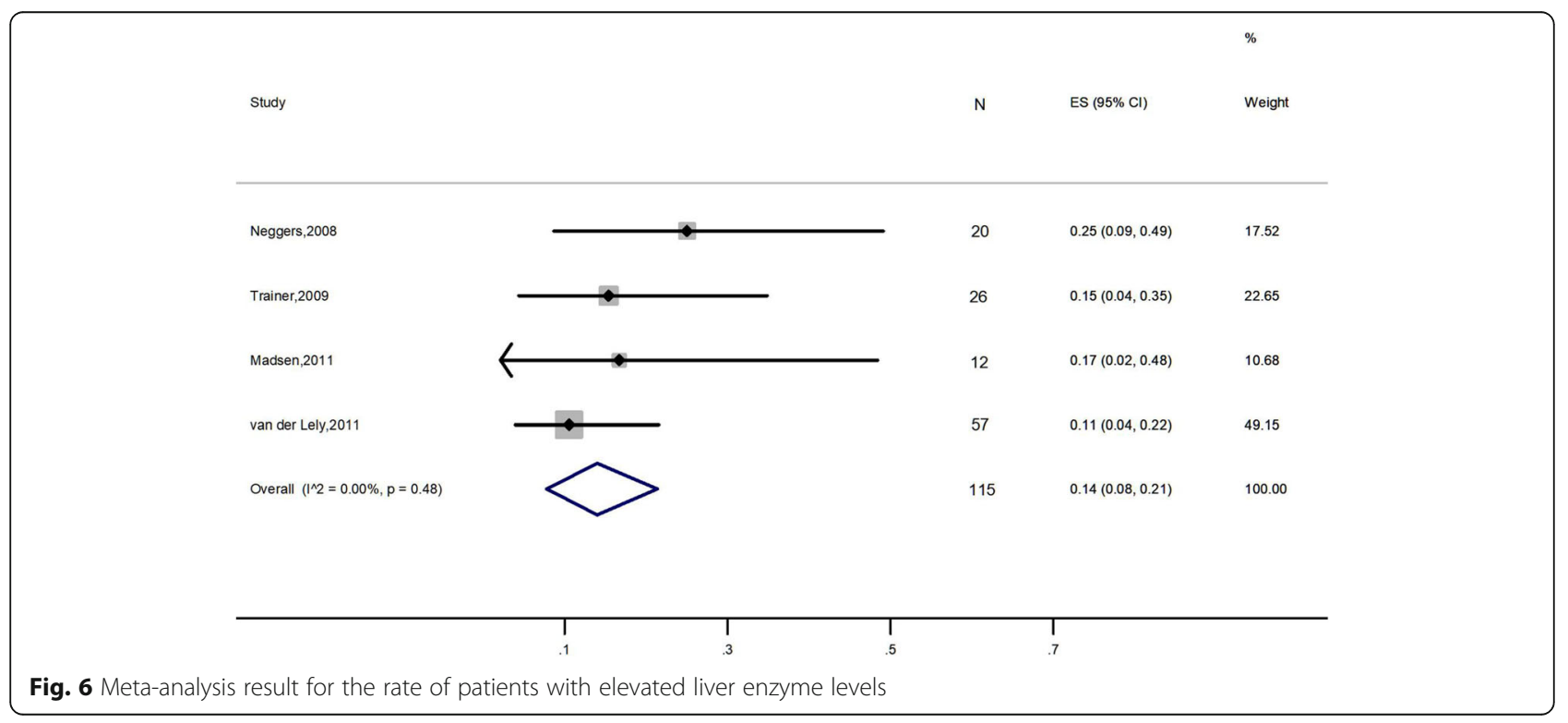


Table 2 Summary of meta-analysis of safety outcomes

\begin{tabular}{|c|c|c|c|c|c|c|c|}
\hline Outcome & Studies & Participants & Statistical method & Effect estimate & $P$-value & $P^{2}(\%)$ & $\begin{array}{l}\text { Evidence } \\
\text { quality }\end{array}$ \\
\hline Serious adverse event & $2[22,25]$ & 92 & Odd ratio $(\mathrm{M}-\mathrm{H}$, Fixed, 95\% Cl) & $0.894[0.102,7.808]$ & 0.919 & 0 & Low \\
\hline $\begin{array}{l}\text { Treatment discontinuation } \\
\text { due to adverse event }\end{array}$ & $2[22,25]$ & 92 & Odd ratio $(\mathrm{M}-\mathrm{H}$, Fixed, 95\% Cl) & $4.288[0.539,34.141]$ & 0.169 & 34.2 & Moderate \\
\hline
\end{tabular}

study with a small population [45] reported that acromegaly patients with diabetes mellitus had a 5.1 times higher risk than nondiabetic subjects for developing transiently elevated liver enzymes, but according to two papers [23, 27] included in this work, there was no relationship between diabetic status and elevated transaminases. Thus, more high-quality studies are needed to clarify their relationship.

The reduced dose of PEG is one of the advantages of this combination therapy. To maintain stable IGF-1 levels during PEG monotherapy, the mean weekly dose has been reported to be approximately $150 \mathrm{mg}$ [44]. In four studies $[2,22,27,28]$ that were included in the analysis of IGF-1 normalization, the median effective weekly PEG doses were $119 \mathrm{mg}, 60 \mathrm{mg}, 80 \mathrm{mg}$ and $105 \mathrm{mg}$. PEG is a much more expensive treatment than high-dose SAs treatment. Hence, we assume that combination therapy is less costly compared with PEG monotherapy.

Our meta-analysis has some limitations. First, most of the included papers are not RCTs. Second, the heterogeneity of some of the meta-analyses is high, and this was partially reduced by sensitivity analyses. Third, we could not get all of data that we were interested in because negative results were not reported and are likely to influence our results. Fourth, few of the analysed studies included patients after previous radiotherapy. The effect of PEG and SAs combination therapy may be partly due to the prolonged effects of radiotherapy on the pituitary function. Last, the number of studies included in the quantitative analyses is not large, but this situation is common when conducting a meta-analysis of a rare disease due to the lack of numerous original trials.

\section{Conclusion}

This meta-analysis investigated the efficacy and safety of combined SAs with PEG therapy on acromegalic patients. Our analysis revealed that the coadministration of SAs and PEG is effective in normalizing IGF-1 levels in patients whose IGF-1 levels are higher than ULN despite high-dose SAs monotherapy. The therapy also decreased significantly FPI levels with a neutral effect on glucose parameters in acromegaly patients. In addition, the combination therapy was found to be safe, although liver function monitoring is still needed during treatment.

\section{Supplementary information}

Supplementary information accompanies this paper at https://doi.org/10. 1186/s12902-020-0545-2.

Additional file 1: Table S1. Full search strategy in database.

Additional file 2: Table S2. Assessment of study quality using Cochrane risk-of-bias algorithm for controlled trials. Table S3. Assessment of study quality using modified Methodological Index for Nonrandomized Studies for non-comparative studies.

Additional file 3: Table S4. Assessment of evidence quality for two safety outcomes.

\section{Abbreviations}

GH: Growth hormone; IGF-1: Insulin-like growth factor 1; SAs: Somatostatin analogues; PEG: Pegvisomant; FPG: Fasting plasma glucose; FPI: Fasting plasma insulin; HbA1c: Glycosylated hemoglobin; Cls: Confidence intervals; ES: Effect size; ULN: Upper limit of normal; SSTR-2: Somatostatin receptors subtype 2; SSTR-5: Somatostatin receptors subtype 5

\section{Acknowledgements}

Not applicable.

\section{Authors' contributions}

DHL and LYM1 (refer to Lingyun Ma) conducted literature search and study selection for this meta-analysis. STW and ML performed data extraction and evaluated study quality. CYC, SZ and LYM2 (refer to Lingyue Ma) verified quality assessment. DHL and LYM1 performed the quantitative meta-analyses and drafted the manuscript with contributions from other authors. TY and YW helped in the interpretation of the results. YZ and YMC were responsible for the projects and participated in its implementation. All authors read and approved the final manuscript.

\section{Authors' information}

$\mathrm{DHL}$ and LYM1's main research interests are clinical pharmacy and clinical pharmacology.

\section{Funding}

This study was funded by The subproject of National Scientific and Technological Major Project for "Significant New Drugs Development": Developing a technology platform for clinical evaluation of demonstrative new drugs for rare diseases in children (Grant No. 2017ZX09304029-006; Grant recipient was YW, who helped in the interpretation of the results), National Scientific and Technological Major Project for "Significant New Drugs Development": The platform of post-marketing evaluation of new drugs for rare diseases (Grant No. 2017ZX09304029-006-001; Grant recipient was $Y Z$, who was responsible for the projects and participated in its implementation.) and The subproject of National Scientific and Technological Major Project for "Significant New Drugs Development": Developing muchneeded drugs for children and applying a industrialization platform (Grant No. 2018ZX09721003-008; Grant recipient was YZ, who was responsible for the projects and participated in its implementation.).

\section{Availability of data and materials}

The data analyzed during the current meta-analysis is available from the corresponding author on reasonable request.

Ethics approval and consent to participate Not applicable. 


\section{Consent for publication}

Not applicable.

\section{Competing interests}

The authors declare that they have no competing interest.

\section{Author details}

'Department of Pharmacy, Peking University First Hospital, No.6, Da Hong Luo Chang Street, Beijing 100034, China. ${ }^{2}$ College of Pharmacy, Peking University Health Science Centre, Beijing, China. ${ }^{3}$ Department of Pediatrics, Peking University First Hospital, Beijing, China.

Received: 1 August 2019 Accepted: 5 May 2020

Published online: 18 August 2020

\section{References}

1. AIDallal S. Acromegaly: a challenging condition to diagnose. Int J Gen Med. 2018;11:337-43

2. Urbani C, Sardella C, Calevro A, et al. Effects of medical therapies for acromegaly on glucose metabolism. Eur J Endocrinol. 2013;169(1):99-108.

3. Colao A, Ferone D, Marzullo P, et al. Systemic complications of acromegaly: epidemiology, pathogenesis, and management. Endocr Rev. 2004;25(1):102-52

4. Katznelson L, Laws ER Jr, Melmed S, et al. Acromegaly: an Endocrine Society clinical practice guideline. J Clin Endocrinol Metab. 2014;99(11):3933-51.

5. Jane JA Jr, Starke RM, Elzoghby MA, et al. Endoscopic Transsphenoidal surgery for acromegaly: remission using modern criteria, complications, and predictors of outcome. J Clin Endocrinol Metab. 2011;96(9):2732-40.

6. Starke RM, Raper DM, Payne SC, et al. Endoscopic vs microsurgical Transsphenoidal surgery for acromegaly: outcomes in a concurrent series of patients using modern criteria for remission. J Clin Endocrinol Metab. 2013; 98(8):3190-8.

7. Giustina A, Chanson P, Kleinberg D, et al. A consensus on the medical treatment of acromegaly. Nat Rev Endocrinol. 2014;10(4):243-8.

8. Carmichael JD, Bonert VS, Nuño M et al. Acromegaly clinical trial methodology impact on reported biochemical efficacy rates of Somatostatin receptor ligand treatments: a Meta-analysis. J Clin Endocrinol Metab. 2014:99(5):1825-33.

9. Colao A, Auriemma RS, Galdiero M, et al. Effects of initial therapy for five years with Somatostatin analogs for acromegaly on growth hormone and insulin-like growth factor-l levels, tumor shrinkage, and cardiovascular disease: a prospective study. J Clin Endocrinol Metab. 2009;94(10):3746-56.

10. Murray RD, Melmed S. A critical analysis of clinically available Somatostatin analog formulations for therapy of acromegaly. J Clin Endocrinol Metab. 2008;93(8):2957-68.

11. Gadelha MR, Bronstein MD, Brue T, et al. Pasireotide versus continued treatment with octreotide or lanreotide in patients with inadequately controlled acromegaly (PAOLA): a randomised, phase 3 trial. Lancet Diabetes Endocrinol. 2014;2(11):875-84.

12. Howlett TA, Willis D, Walker G, et al. Control of growth hormone and IGFI in patients with acromegaly in the UK: responses to medical treatment with somatostatin analogues and dopamine agonists. Clin Endocrinol. 2013;79(5): 689-99.

13. Kopchick JJ, Parkinson C, Stevens EC, et al. Growth hormone receptor antagonists: discovery, development, and use in patients with acromegaly. Endocr Rev. 2002;23(5):623-46.

14. van der Lely AJ, Biller BMK, Brue T, et al. Long-term safety of Pegvisomant in patients with acromegaly: comprehensive review of 1288 subjects in ACROSTUDY. J Clin Endocrinol Metab. 2012;97(5):1589-97.

15. Leonart LP, Tonin FS, Ferreira $V L$, et al. Effectiveness and safety of pegvisomant: a systematic review and meta-analysis of observational longitudinal studies. Endocrine. 2019;63(1):18-26.

16. Neggers SJ, van der Lely AJ. Combination treatment with somatostatin analogues and pegvisomant in acromegaly. Growth Hormon IGF Res. 2011; 21(3):129-33.

17. Strasburger CJ, Mattsson A, Wilton $\mathrm{P}$, et al. Increasing frequency of combination medical therapy in the treatment of acromegaly with the $\mathrm{GH}$ receptor antagonist pegvisomant. Eur J Endocrinol. 2018;178(4):321-9.

18. Tiziana F, Alessia C, llaria $\mathrm{S}$, et al. Pegvisomant improves glucose metabolism in acromegaly: a meta analysis of prospective interventional studies. J Clin Endocrinol Metab. 2019;104(7):2892-902.
19. Higgins JP, Altman DG, Gøtzsche PC, et al. The Cochrane Collaboration's tool for assessing risk of bias in randomised trials. BMJ. 2011;343:d5928.

20. Slim K, Nini E, Forestier D, et al. Methodological index for non-randomized studies (MINORS): development and validation of a new instrument. ANZ J Surg. 2003;73:712-6.

21. Higgins JP, Thompson SG, Deeks JJ, et al. Measuring inconsistency in metaanalyses. BMJ. 2003;327(7414):557-60.

22. Trainer PJ, Ezzat S, D'Souza GA, et al. A randomized, controlled, multicentre trial comparing pegvisomant alone with combination therapy of pegvisomant and long-acting octreotide in patients with acromegaly. Clin Endocrinol. 2009;71(4):549-57.

23. Neggers SJ, van Aken MO, de Herder WW, et al. Quality of life in Acromegalic patients during long-term Somatostatin analog treatment with and without Pegvisomant. J Clin Endocrinol Metab. 2008;93(10):3853-9.

24. Madsen M, Poulsen PL, Orskov H, et al. Cotreatment with Pegvisomant and a Somatostatin analog (SA) in SA-responsive Acromegalic patients. J Clin Endocrinol Metab. 2011:96(8):2405-13.

25. Colao A, Zgliczyński W, Komorowski J, et al. Efficacy and safety of high-dose long-acting repeatable octreotide as monotherapy or in combination with pegvisomant or cabergoline in patients with acromegaly not adequately controlled by conventional regimens: results of an open-label, multicentre study. Endokrynologia Polska. 2019;70(4):305-12.

26. Muhammad A, Coopmans EC, Delhanty PJD, et al. Efficacy and safety of switching to pasireotide in acromegaly patients controlled with pegvisomant and somatostatin analogues: PAPE extension study. Eur J Endocrinol. 2018;179(5):269-77.

27. van der Lely A, Bernabeu I, Cap J, et al. Coadministration of lanreotide autogel and pegvisomant normalizes IGF1 levels and is well tolerated in patients with acromegaly partially controlled by somatostatin analogs alone. Eur J Endocrinol. 2011:164(3):325-33.

28. Auriemma RS, Grasso LF, Galdiero M, et al. Effects of long-term combined treatment with somatostatin analogues and pegvisomant on cardiac structure and performance in acromegaly. Endocrine. 2017:55(3):872-84

29. Jørgensen JO, Feldt-Rasmussen U, Frystyk J, et al. Cotreatment of acromegaly with a Somatostatin analog and a growth hormone receptor antagonist. J Clin Endocrinol Metab. 2005:90(10):5627-31.

30. Hannon AM, Thompson CJ, Sherlock M. Diabetes in patients with acromegaly. Curr Diab Rep. 2017:17:8.

31. Mazziotti G, Floriani I, Bonadonna S, et al. Effects of Somatostatin analogs on glucose homeostasis: a Metaanalysis of acromegaly studies. J Clin Endocrinol Metab. 2009;94(5):1500-8.

32. Cozzolino A, Feola T, Simonelli I, et al. Somatostatin analogs and glucose metabolism in acromegaly: a Meta-analysis of prospective interventional studies. J Clin Endocrinol Metab. 2018;103(6):2089-99.

33. Giustina A, Mazziotti G, Maffezzoni F, et al. Investigational drugs targeting somatostatin receptors for treatment of acromegaly and neuroendocrine tumors. Expert Opin Investig Drugs. 2014:23(12):1619-35.

34. Singh V, Brendel MD, Zacharias S, et al. Characterization of somatostatin receptor subtype-specific regulation of insulin and glucagon secretion: an in vitro study on isolated human pancreatic islets. J Clin Endocrinol Metab. 2007:92(2):673-80.

35. Hansen L, Hartmann B, Bisgaard T, et al. Somatostatin restrains the secretion of glucagon-like peptide-1 and -2 from isolated perfused porcine ileum. Am J Physiol Endocrinol Metab. 2000;278(6):E1010-8.

36. Schreiber I, Buchfelder M, Droste M, et al. Treatment of acromegaly with the $\mathrm{GH}$ receptor antagonist Pegvisomant in clinical practice: safety and efficacy evaluation from the German Pegvisomant observational study. Eur J Endocrinol. 2007;156(1):75-82.

37. Drake WM, Rowles SV, Roberts ME, et al. Insulin sensitivity and glucose tolerance improve in patients with acromegaly converted from depot octreotide to Pegvisomant. Eur J Endocrinol. 2003;149(6):521-7.

38. Ghigo E, Biller BM, Colao A, et al. Comparison of Pegvisomant and long acting octreotide in patients with acromegaly naive to radiation and medical therapy. J Endocrinol Investig. 2009:32(11):924-33.

39. Lindberg-Larsen R, Møller N, Schmitz O, et al. The impact of Pegvisomant treatment on substrate metabolism and insulin sensitivity in patients with acromegaly. J Clin Endocrinol Metab. 2007;92(5):1724-8.

40. De Laura M, Antonio B, Alessandra F, et al. Long-term effects of the combination of pegvisomant with somatosatin analogs (SSA) on glucose homeostasis in non-diabetic patients with active acromegaly partially resistant to SSA. Pituitary. 2007;10:227-32. 
41. Gadelha R. Monica, Bronstein D Marcello, Brue Thierry, et al. Pasireotide versus continued treatment with octreotide or lanreotide in patients with inadequately controlled acromegaly (PAOLA): a randomized, phase 3 trial. Lancet Diab Endocrinol. 2014;2(11):875-84.

42. Gadelha MR, Wildemberg LE, Bronstein MD, et al. Somatostatin receptor ligands in the treatment of acromegaly. Pituitary. 2017;20(1):100-8.

43. Giustina A, Ambrosio MR, Beck Peccoz P, et al. Use of Pegvisomant in acromegaly. An Italian Society of Endocrinology guideline. J Endocrinol Investig. 2014;37(10):1017-30.

44. Maffei P, Martini C, Pagano C, et al. Lipohypertrophy in acromegaly induced by the new growth hormone receptor antagonist Pegvisomant. Ann Intern Med. 2006;145(4):310-2.

45. Neggers SJ, van Aken MO, Janssen JA, et al. Long-term efficacy and safety of combined treatment of Somatostatin analogs and Pegvisomant in acromegaly. J Clin Endocrinol Metab. 2007:92(12):4598-601.

\section{Publisher's Note}

Springer Nature remains neutral with regard to jurisdictional claims in published maps and institutional affiliations.

Ready to submit your research? Choose BMC and benefit from:

- fast, convenient online submission

- thorough peer review by experienced researchers in your field

- rapid publication on acceptance

- support for research data, including large and complex data types

- gold Open Access which fosters wider collaboration and increased citations

- maximum visibility for your research: over $100 \mathrm{M}$ website views per year

At BMC, research is always in progress.

Learn more biomedcentral.com/submissions 